\title{
Latitudinal and interhemispheric differences of the ionospheric semi-diurnal lunitidal perturbations during the 2009 Arctic sudden stratospheric warming event in the eastern Asia-Australia sector
}

\author{
Jing Liu', Donghe Zhang ${ }^{1 *} \mathbb{B}$, Shuji Sun², Yongqiang Hao ${ }^{1}$ and Zuo Xiao ${ }^{1}$
}

\begin{abstract}
The ionosphere exhibits some characteristic perturbations during sudden stratospheric warming (SSW) events, of which the mechanism is not thoroughly understood. This study focuses on the latitudinal and interhemispheric differences of the enhanced semi-diurnal lunitidal (M2) perturbations related to SSW using total electron content calculated from the network of Global Navigation Satellite System and ionosonde data in the eastern Asia-Australia sector during the January 2009 SSW. Our results show that the most distinct M2 perturbations in the northern and southern hemispheres occur near the Equatorial Ionization Anomaly crest regions around $\pm 15^{\circ}$ geomagnetic latitudes, but corresponds to different moon phases, respectively. Clear M2 perturbations extend to middle latitudes only in the southern hemisphere and have another local maximum in the southern middle latitude. Such latitudinal and interhemispheric features of ionospheric M2 perturbations in the low latitude in the eastern Asia-Australia sector are similar as those in the American sector during the same SSW event. This supports previous suggestion that such latitudinal and interhemispheric differences in the low latitude can be primarily explained by the summer-winter thermospheric wind modulation on equatorial plasma fountain and thus emphasize its role in the vertical coupling process of $\mathrm{M} 2$ perturbation. The clear differences of $\mathrm{M} 2$ perturbations in the southern middle latitude between the eastern Asia-Australia and American sectors indicate that the thermospheric circulation related to the Weddell Sea Anomaly may have influence on the lower atmosphere-ionosphere coupling.
\end{abstract}

Keywords: Sudden stratospheric warming, lonospheric perturbation, Semi-diurnal lunar tide, Latitudinal difference, Interhemispheric difference

*Correspondence: zhangdh@pku.edu.cn

1 School of Earth and Space Sciences, Peking University, Beijing, China

Full list of author information is available at the end of the article 

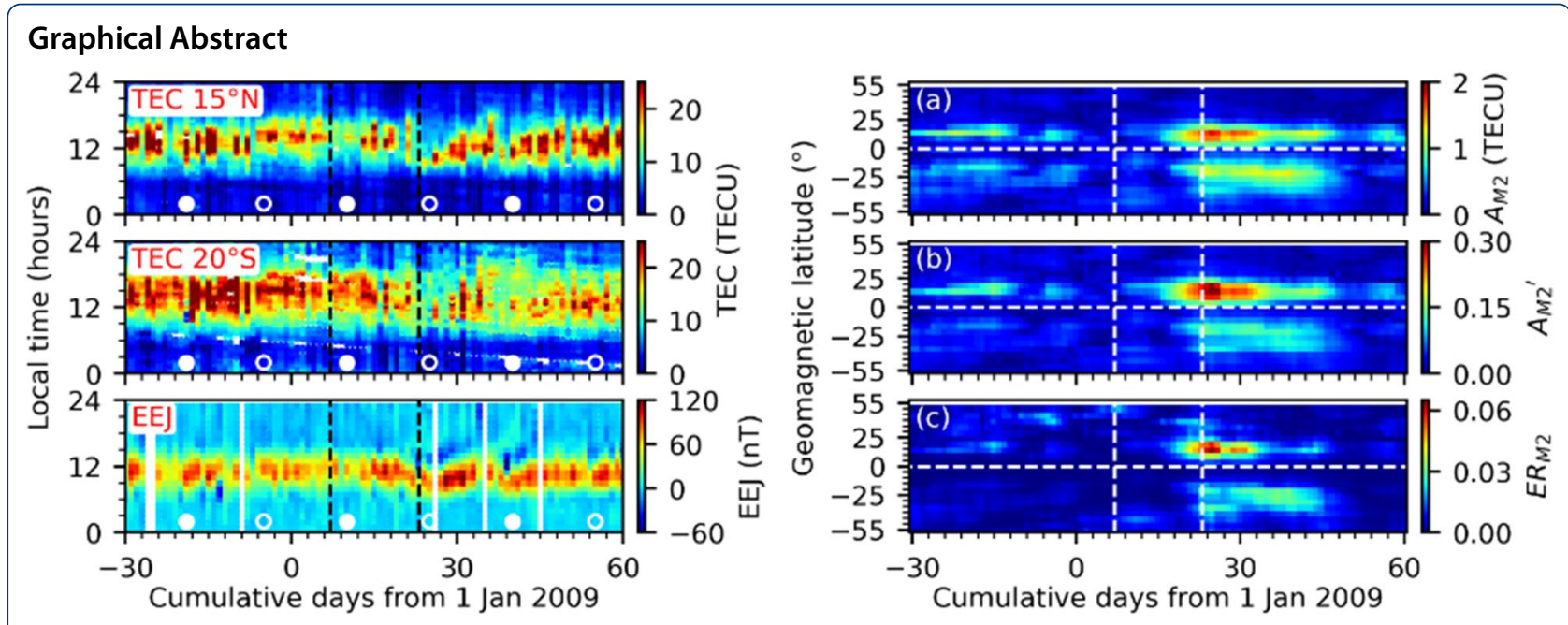

\section{Introduction}

Sudden stratospheric warming (SSW) is a polar stratospheric phenomenon caused by the interaction between planetary wave (PW) and polar stratospheric vortex, characterized by the rapid increase of temperature and the decrease or even reversal of zonal mean zonal wind (Matsuno, 1971; Butler et al., 2015). Interestingly, the SSW-related perturbations are not restricted to polar stratosphere, but were observed from high to low latitudes and from the troposphere to the ionosphere (Siddiqui et al., 2021; and reference therein). During the SSW, ionospheric parameters exhibit characteristic perturbations that could reach about $50 \sim 100 \%$ of the background value (Pedatella et al., 2016). These SSW-related ionospheric perturbations were demonstrated to be related to lower-atmosphere waves from observations and numerical simulations (Goncharenko and Zhang; 2008; Chau et al., 2009; Vineeth et al., 2009; Fejer et al., 2010; Pedatella et al., 2016). Thus, related studies benefit our understating of ionospheric variability during quiet times. Nevertheless, most related studies focused on the low latitudes considering that the SSW-related perturbations are more significant in this region. Comparatively, studies of the manifestation and mechanism of SSW-related ionospheric perturbations in other regions are limited.

Among different kinds of ionospheric perturbations during SSWs, the semi-diurnal lunitidal (M2) perturbation is one of the most concerned (Fejer et al., 2010; Forbes and Zhang, 2012; Yamazaki et al., 2012; Pedatella et al., 2014; Mo and Zhang, 2018; Liu et al., 2019). A typical signature of the ionospheric M2 perturbation is the phase-shifted semi-diurnal (PSSD) variation pattern described by Fejer et al., (2010). The M2 explanation of the ionospheric PSSD variation pattern during SSWs was supported by various studies with observations and simulations (Forbes and Zhang, 2012; Park et al., 2012; Pedatella et al., 2012b; Xiong et al., 2013). In observations, the good correspondence between the ionospheric PSSD variation patterns and the moon phases strongly supported the importance of M2 during SSWs (Fejer et al., 2010; Liu et al., 2019). Nevertheless, some simulation studies suggested that the generation of the ionospheric PSSD variation pattern may also be contributed by the phase-shifting of solar tides (Fuller-Rowell et al., 2011, 2016; Fang et al., 2012, 2014). Obviously, the study on the ionospheric PSSD perturbations is helpful for our understanding of the coupling processes between the lower atmosphere and ionosphere. Forbes and Zhang (2012) suggested that the enhancement of ionospheric M2 perturbations during SSWs is due to the shift of the atmospheric Pekeris resonance peak to $12.43 \mathrm{~h}$ due to the zonal mean wind changes related to SSWs. Nevertheless, it is not thoroughly understood what causes the difference of the M2 perturbations between different ionospheric regions, especially the latitudinal and interhemispheric differences since most related studies focused on low latitudes.

The latitudinal and interhemispheric differences of the ionospheric M2 perturbations have drawn much attention (Goncharenko et al., 2010, 2013; Liu et al., 2011, 2021; Fagundes et al., 2015; Mo et al., 2017; Pedatella and Maute, 2015; Yue et al., 2010). Such differences were considered to be related to different background features and coupling mechanism. In the daytime low latitudes, the equatorial plasma fountain plays an important role in the vertical coupling process of lower-atmosphere waves (Goncharenko et al., 2010, 2013; Pedatella et al., 2012b, 2014). The direct upward penetration of 


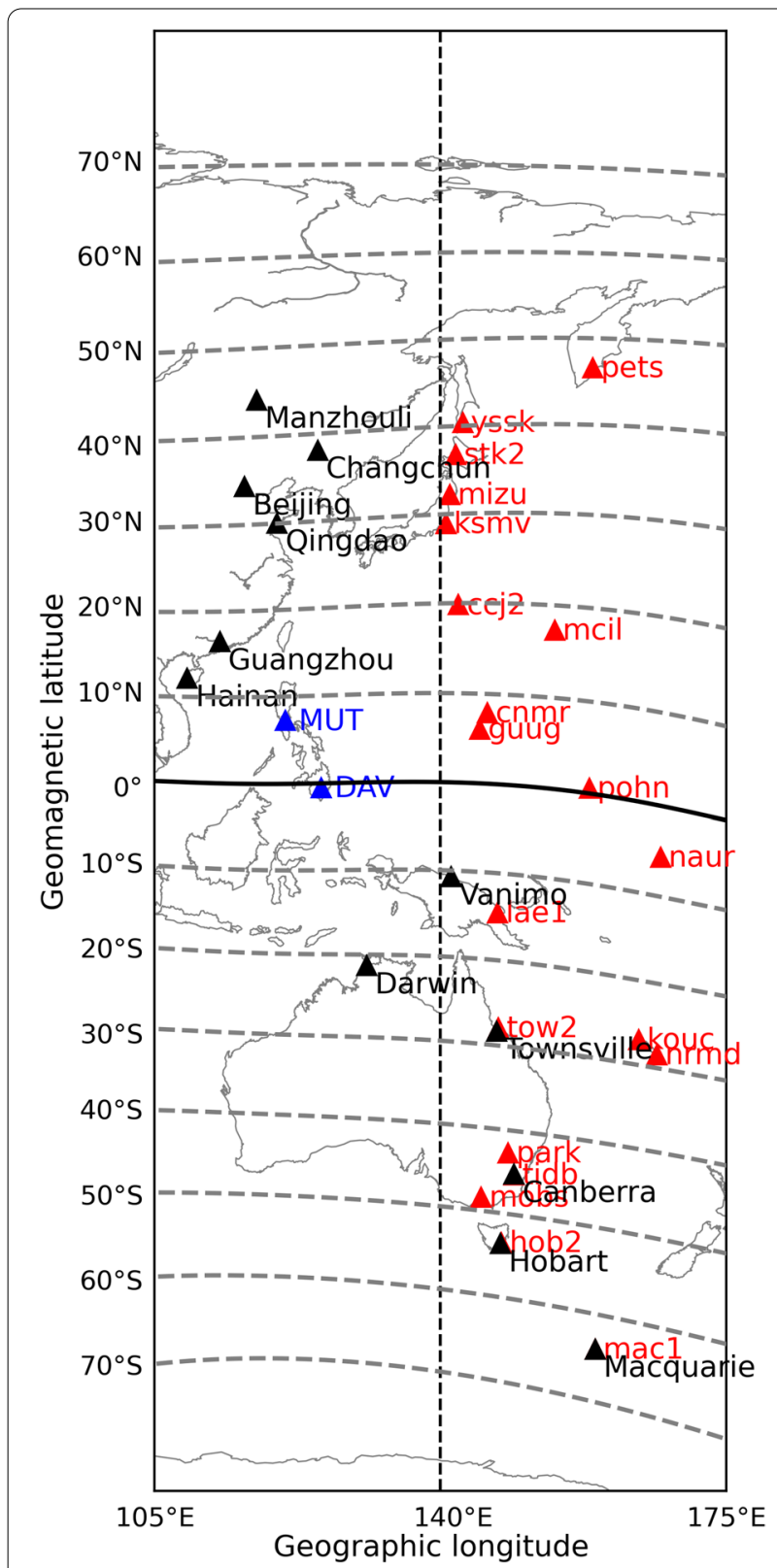

Fig. 1 The locations of the used ground-based observation stations. The curved dashed and solid lines represent the geomagnetic latitudes. The GNSS, ionosonde, and magnetometer stations are illustrated with red, black, and blue triangles, respectively

lower-atmosphere waves and their in situ dynamics in the ionosphere are also considered, especially in the middle and high latitudes (Goncharenko and Zhang, 2008; Park and Lühr, 2012; Pedatella and Maute, 2015). With ground-based TEC data across the American continents, Liu et al. (2021) analyzed the latitudinal distribution of the M2 perturbation enhancement during three major SSWs. The observed distribution is mainly attributed to the meridional wind effect on the equatorial plasma fountain while the direct penetration mechanism may be important in the southern middle latitudes. Nevertheless, they emphasized that such an explanation was drawn based on observations in the American sector, which has unique geomagnetic, atmospheric, and ionospheric conditions. Thus, similar studies in other longitudinal sectors are encouraged as comparison.

The eastern Asia-Australia sector also has groundbased ionospheric observation network across both hemispheres with relatively good resolutions. The geomagnetic field configuration, atmospheric waves activities, and the background ionospheric features in the eastern Asia-Australia sector significantly differs from those in the American sector (Liu et al., 2020). The 2009 SSW is one of the strongest SSW events in record with quiet solar and geomagnetic activities (Manney et al., 2009; Yamazaki et al., 2020, and reference therein), which benefits the analysis of the lower-atmosphere influence to the ionosphere during the SSW. Thus, the present paper analyzes the latitudinal and interhemispheric differences of the ionospheric M2 perturbations during the 2009 SSW based on multi-latitude ionospheric observations in the eastern Asia-Australia sector.

\section{Data and methods}

Global Navigation Satellite System (GNSS), ionosonde, and magnetometer data are utilized to derive the ionospheric parameters in the eastern Asia-Australia sector. Figure 1 shows the locations of the used ground-based observation stations. The curved dashed and solid lines represent the geomagnetic latitudes from the Corrected Geomagnetic Coordinates (Shepherd, 2014), which are also used hereinafter. Details are as follows.

Now, the GNSS network is a traditional ionospheric data resource. Studies based on the GNSS network data greatly improved our understanding of the ionospheric morphology and disturbance globally (Ho et al., 1996; Saito et al., 1998; Tsugawa et al., 2003; Zhang and Xiao, 2005). In this study, the ionospheric total electron content (TEC) data are calculated from the GNSS data from the International GNSS Service. The locations of the used GNSS stations are shown in Fig. 1 with red triangles with the corresponding code names beside. The ionospheric vertical TEC data at each ionospheric pierce point are calculated with the method described in Zhang et al. (2009) and Zhang et al. (2010). During the calculation, the cutoff elevation angle of satellites is set to be $15^{\circ}$. Then, the mean vertical TEC is calculated in each 5-degreewide latitudinal band from $55^{\circ} \mathrm{N}$ to $55^{\circ} \mathrm{S}$ geomagnetic latitudes with a 5-degree interval (i.e., $0^{\circ} \pm 2.5^{\circ}, \pm 5^{\circ} \pm 2.5^{\circ}$, $\ldots, \pm 55^{\circ} \pm 2.5^{\circ}$ ) for every 0.5 -h local time. 
The ionospheric foF2 data from ionosonde stations affiliated to the China Research Institute of Radio-wave Propagation and Australian Government Bureau of Meteorology, respectively, are utilized. The locations of the used ionosonde stations are shown in Fig. 1 with black triangles.

The equatorial electrojet (EEJ) strength data are estimated with the difference of the horizontal component of the geomagnetic field between two ground-based magnetometers on and aside the geomagnetic equator (Kane, 1973; Rastogi and Klobuchar, 1990). This parameter is also suggested to be a good proxy of the equatorial vertical drift velocity considering their good linear relationship (Anderson et al., 2002). The used stations are DAV $\left(125.40^{\circ} \mathrm{E}, 7.00^{\circ} \mathrm{N} ; 0.52^{\circ} \mathrm{S}\right.$ geomagnetic latitude) and MUT $\left(121.02^{\circ} \mathrm{E}, 14.37^{\circ} \mathrm{N} ; 7.13^{\circ} \mathrm{N}\right.$ geomagnetic latitude) from the Magnetic Data Acquisition System and their locations are shown in Fig. 1 with blue triangles.

The mean vertical TEC and ionosonde data are decomposed into tidal components through a least-square fitting method (Xiong et al., 2013). Taking TEC for example, the used equation is

$$
\begin{aligned}
\mathrm{TEC}= & \mathrm{TEC}_{0}+a_{1} \cos \left(\frac{2 \pi}{24} t\right)+b_{1} \sin \left(\frac{2 \pi}{24} t\right) \\
& +a_{2} \cos \left(\frac{2 \pi}{12} t\right)+b_{2} \sin \left(\frac{2 \pi}{12} t\right) \\
& +a_{3} \cos \left(\frac{2 \pi}{8} t\right)+b_{3} \sin \left(\frac{2 \pi}{8} t\right) \\
& +a_{4} \cos \left(\frac{2 \pi}{12.42} t\right)+b_{4} \sin \left(\frac{2 \pi}{12.42} t\right),
\end{aligned}
$$

where $T E C_{0}$ is the mean TEC and $t$ is the cumulative solar local-time hours from 00:00 LT, January 1, 2009. Note that only four tidal components (solar diurnal, S1, $24 \mathrm{~h}$; solar semi-diurnal, S2, $12 \mathrm{~h}$; solar terdiurnal, $8 \mathrm{~h}$; lunar semi-diurnal, M2, $12.42 \mathrm{~h}$ ) are considered since they were demonstrated to be most dominant in the ionosphere during SSWs (Sathishkumar and Sridharan, 2013; Lin et al., 2012; Pedatella and


Fig. 2 The stratospheric polar temperature and wind, the planetary wave activity, and the solar and geomagnetic indices as a function of cumulative days from 1 January 2009. a $T$ (red) is the temperature at $90^{\circ} \mathrm{N}, 10 \mathrm{hPa}$ and $U$ is the zonal mean zonal wind at $60^{\circ} \mathrm{N}, 10 \mathrm{hPa}$. The vertical dashed lines mark the initiation dates of the decrease and reversal of $U . \mathbf{b} Z 1$ and $Z 2$ are the planetary-wave amplitudes of zonal wavenumber 1 and 2 components, respectively, calculated from the geopotential height at $60^{\circ} \mathrm{N}, 10 \mathrm{hPa}$. c The $K p$ (blue) and F10.7 (red) indices 


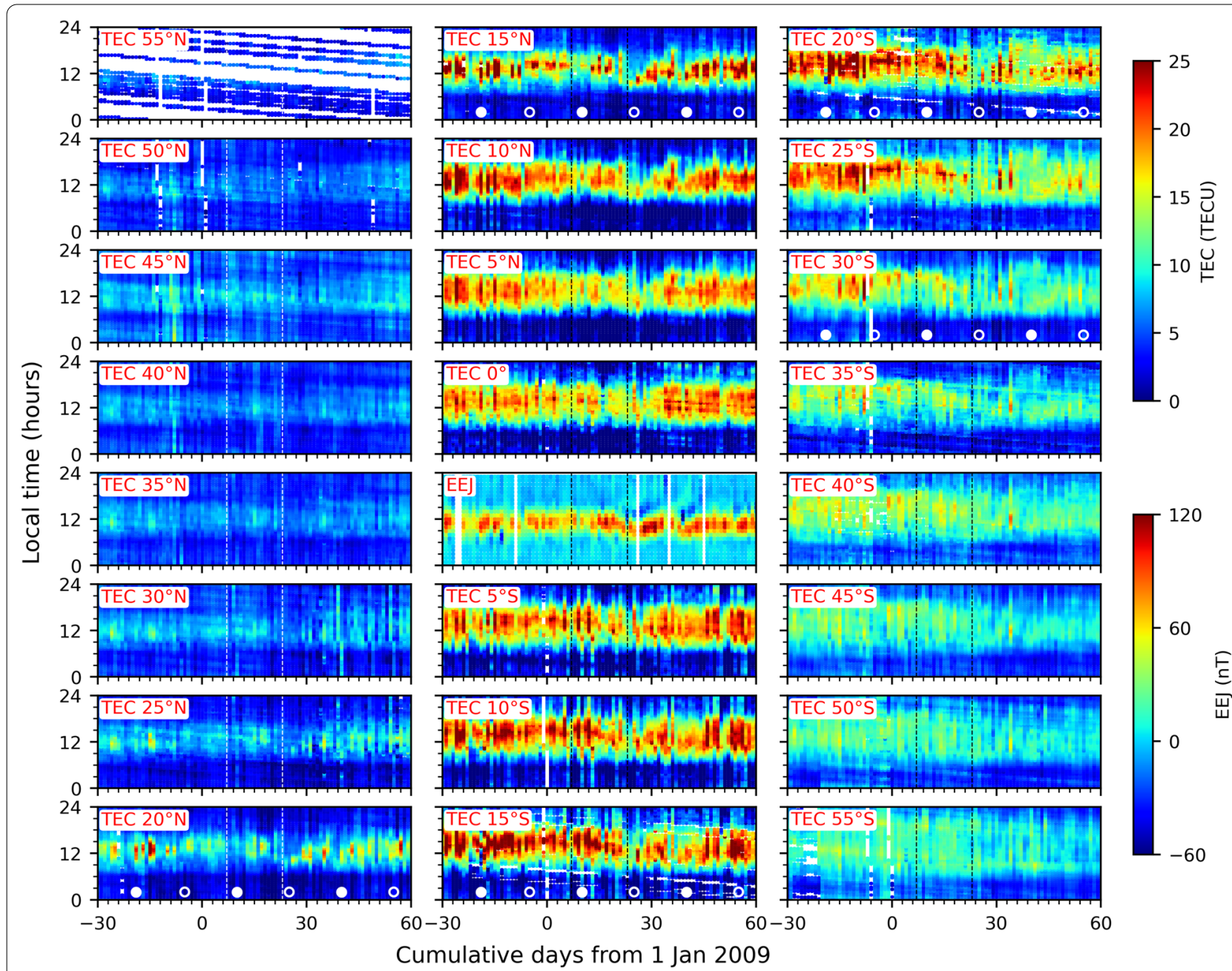

Fig. 3 The vertical TEC and EEJ strength data as a function of cumulative days from 1 January 2009 and solar local time over the eastern AsiaAustralia sector at different geomagnetic latitudes. The vertical dashed lines are the same as those in Fig. 2a. The white dots and circles indicate the dates of the full moon and the new moon

Forbes, 2010; Fuller-Rowell et al., 2011; Fejer et al., 2010; Xiong et al., 2013). The decomposition is carried out in a 17-day running window. It enables our analysis to separate M2 from S2 while almost maximize the temporal resolution cause 17 days are slightly longer than $\delta T=14.8$ days $\left(1 / \delta T<f_{S 2}-f_{M 2} \approx 1 / 14.8\right.$ cycle per day $)$ (He et al., 2018). The tidal amplitudes are $A_{n}=\sqrt{a_{n}^{2}+b_{n}^{2}}$ and are further normalized as $A_{n}{ }^{\prime}=A_{n} / \mathrm{TEC}_{0}$ for facilitating latitudinal comparisons. The tidal phase $P_{n}$ is defined as the local time when the tidal amplitude reaches its maximum (Xiong et al., 2013). Finally, the energy ratio of the M2 component to the solar tidal components is defined as $E R_{M 2}=A_{M 2}{ }^{2} /\left(A_{S 1}{ }^{2}+A_{S 2}{ }^{2}+A_{S 3}{ }^{2}\right)$, which provides a measurement of the relative magnitude of M2 in comparison with solar tides.
In addition, the polar stratospheric temperature, zonal wind, and geopotential height data from the National Centers for Environmental Prediction are used to characterize the 2009 SSW event (Butler et al., 2015). The Kp and F10.7 indices from the OMNI dataset are used to describe the geomagnetic and solar activities.

\section{Results}

Figure 2 shows the stratospheric polar temperature and wind, the planetary wave activity, and the solar and geomagnetic indices as a function of cumulative days from 1 January 2009. Figure 2a shows the temperature at $90^{\circ} \mathrm{N}$, $10 \mathrm{hPa}\left(T\right.$, red) and the zonal mean zonal wind at $60^{\circ} \mathrm{N}$, $10 \mathrm{hPa}(U$, blue). The vertical dashed lines mark the initiation dates of the decrease and reversal of $U$. The rapid increase in $T$ and the reversal in $U$ around day 23 




Fig. 4 The variations of $A_{M 2}, A_{M 2}{ }^{\prime}, E R_{M 2}, A_{S 1}, A_{S 2}, A_{S 3}$, and $T E C_{0}$ (a to g) calculated with Eq. (1) from TEC data in Fig. 3. The vertical dashed lines are the same as those in Fig. 2a. The horizontal dashed lines represent the geomagnetic equator

characterize a major SSW (Butler et al., 2015). Figure 2b shows the PW amplitudes of zonal wavenumber 1 (Z1, solid) and 2 (Z2, dashed) components from the geopotential height at $60^{\circ} \mathrm{N}, 10 \mathrm{hPa}$. It indicates that the 2009 major Arctic SSW is mainly caused by the enhancement of the Z2 component (Goncharenko et al., 2010). Figure 2c shows the $K p$ (blue) and $F 10.7$ (red) indices during the studied period. Clearly, the geomagnetic and solar activities are quiet around the 2009 SSW.

Figure 3 gives the vertical TEC as a function of cumulative days from 1 January 2009 and solar local time over the eastern Asia-Australia sector at different geomagnetic latitudes. The EEJ strength variation is also given as a comparison. The vertical dashed lines are the same as those in Fig. 2a that mark the characteristic dates of the 2009 SSW. The white dots and circles indicate the dates of the full moon and the new moon. It shows that two cycles of PSSD perturbations occur in TEC and EEJ that follow the occurrence of the SSW and synchronize well with the moon phase. Such a correspondence indicates that the PSSD perturbations are related to the lunar tide. The most distinct PSSD perturbations occur around the EIA crest regions. In the north hemisphere, the PSSD signatures are less identifiable above $25^{\circ} \mathrm{N}$ geomagnetic latitude; while in the southern hemisphere, the PSSD signatures can still be identified to around $35^{\circ} \mathrm{S}$ geomagnetic latitude.

Figure 4 gives $A_{M 2}, A_{M 2}, E R_{M 2}, A_{S 1}, A_{S 2}, A_{S 3}$, and $T E C_{0}$ from (a) to (g) calculated with Eq. (1). The vertical dashed lines are the same as those in Fig. 2a. The horizontal dashed lines represent the geomagnetic equator. Figure $4 \mathrm{a}-\mathrm{c}$ shows that the $A_{M 2}, A_{M 2}$, and $E R_{M 2}$ enhancements follow the occurrence of the SSW and correspond to the PSSD signatures in Fig. 3. The enhancement of TEC M2 perturbation has largest magnitude around the Equatorial Ionization Anomaly (EIA) crest regions in both hemispheres and is relatively larger in the northern hemisphere than in the southern hemisphere. In the northern and southern hemispheres, the largest M2 perturbations occur around day 25 and day 39, respectively, which correspond to the first and second cycles of the PSSD signatures in Fig. 3. Besides, clear enhancement of TEC M2 perturbations exhibits a wider latitudinal range in the southern hemisphere than in the northern hemisphere. It is interesting to note that the $A_{M 2}, A_{M 2}$, and $E R_{M 2}$ have local maxima at $35^{\circ} \mathrm{S}$ around day 25 and will be discussed in Sect. 4. Comparatively, the SSW dependence of the $A_{S 1}, A_{S 2}$, and $A_{S 3}$ variations in TEC is not as clear as that of $A_{M 2}$. Nevertheless, it is worth noting that solar-tide amplitudes seem to decrease following the SSW. This reflects the TEC suppression during the same period in Fig. 3 and similar manifestation has also been reported during the $2009 \mathrm{SSW}$ in the American sector (Fagundes et al., 2015).

As a comparison to the TEC results, Fig. 5 gives the variations of $f o F 2$ data (left column) and the corresponding $A_{M 2}$ (right column) from a chain of ionosonde stations in the eastern Asia-Australia sector. The locations and geomagnetic latitudes of these stations are shown in the right column. The missing parts of $A_{M 2}$ data in certain plots are due to insufficient $f o F 2$ data points for the calculation during corresponding periods. The vertical dashed lines are the same as those in Fig. 2a. It shows that the latitudinal and interhemispheric differences of PSSD perturbations in $f o F 2$ are generally consistent with those in TEC. Specifically, the largest $A_{M 2}$ in the northern hemisphere occurs in Guangzhou around day 25 while the largest $A_{M 2}$ in the southern hemisphere occurs in Darwin around day 39 , which is similar as the TEC results described hereinabove. 


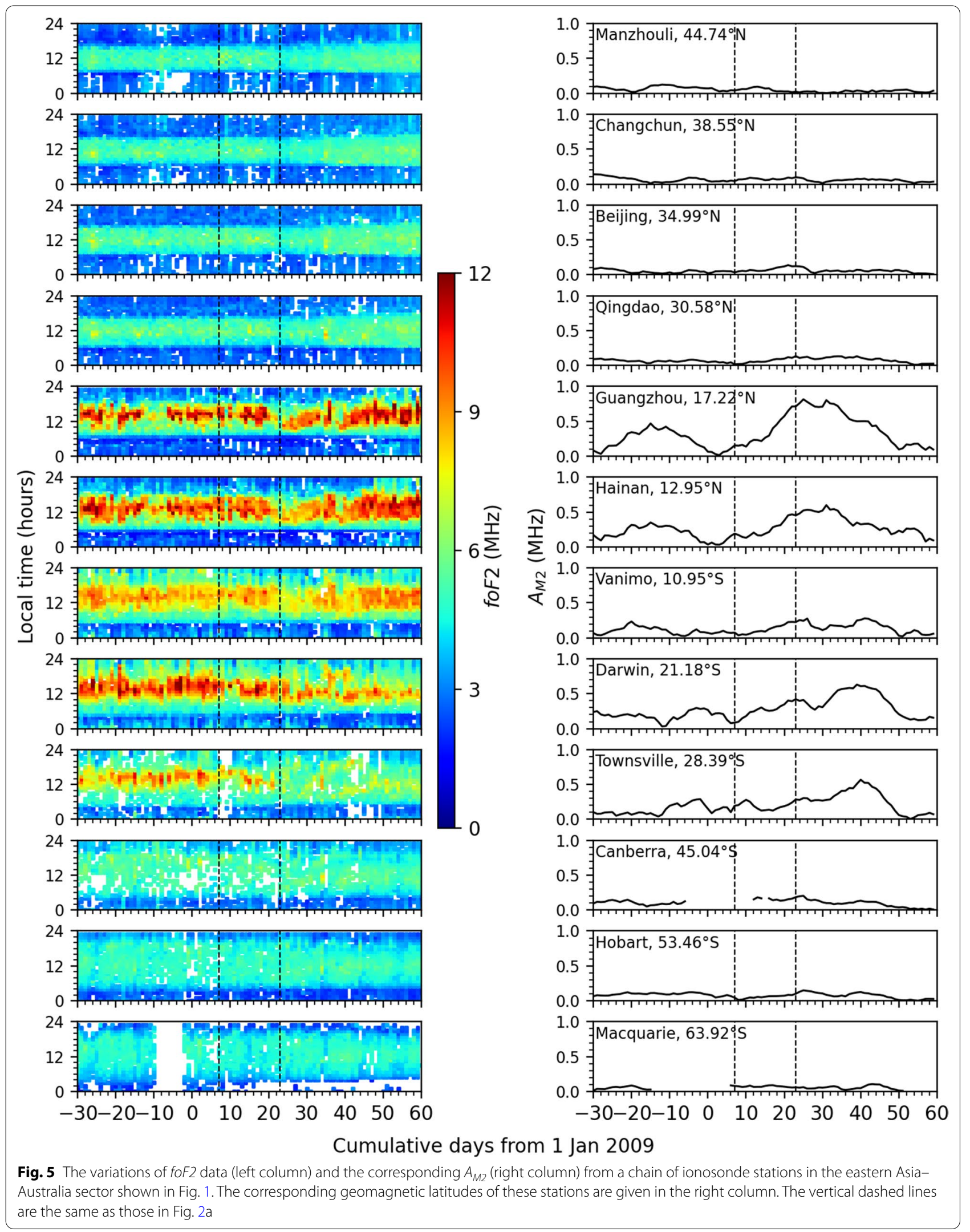



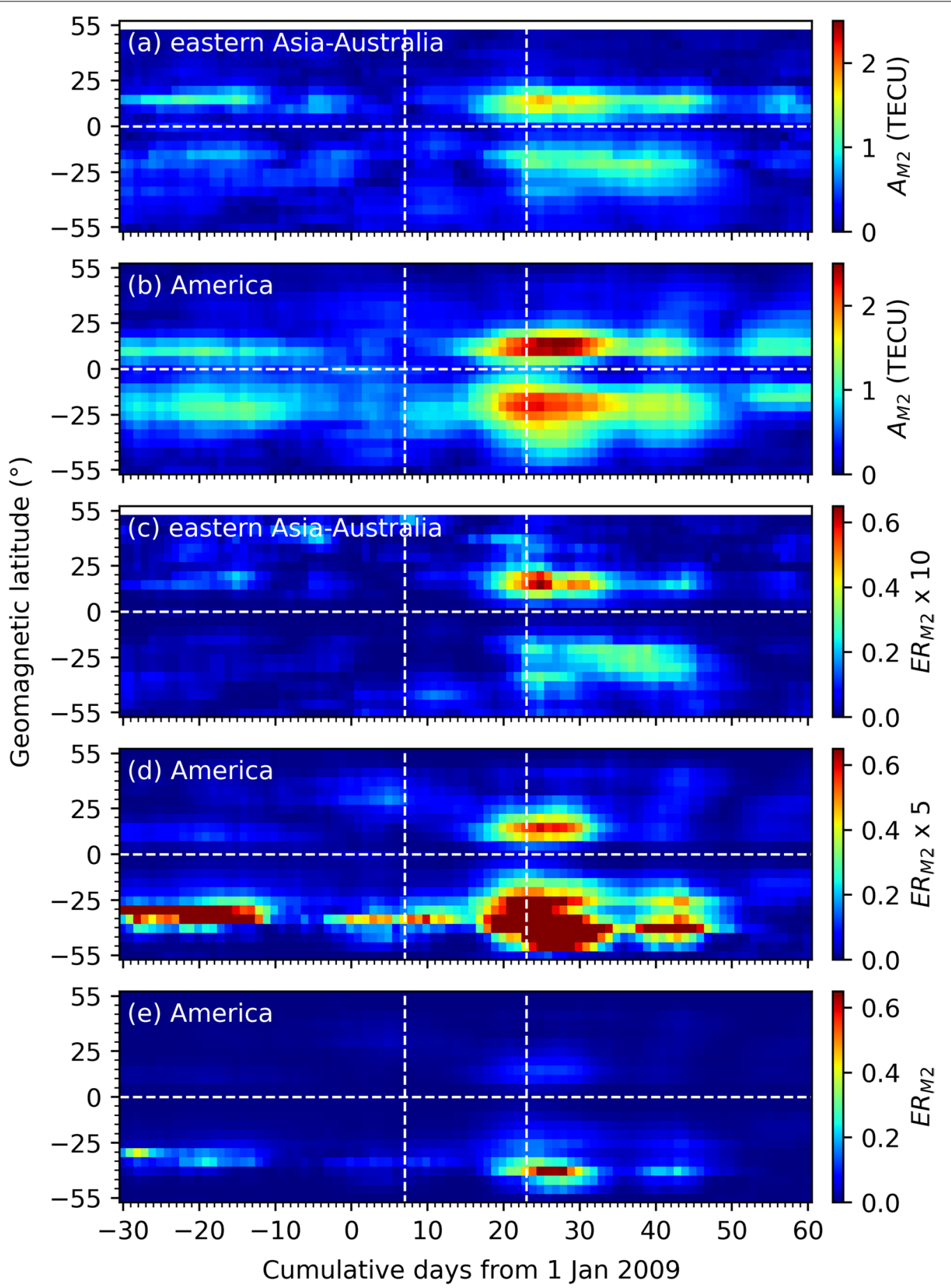

Fig. 6 The variations of $A_{M 2}$ and $E R_{M 2}$ in the eastern Asia-Australia and American sectors during the 2009 SSW. The vertical dashed lines are the same as those in Fig. 2a. The horizontal dashed lines represent the geomagnetic equator

\section{Discussion}

Our results show that $A_{M 2}, A_{M 2}$, and $E R_{M 2}$ in the eastern Asia-Australia TEC enhanced during the 2009 SSW with largest magnitude in the EIA crest regions, larger magnitude in the northern hemisphere, and wider latitudinal range in the southern hemisphere. The ionospheric perturbation signatures reflected from our results are partly consistent with some studies focusing on regional 
ionospheric variations during different SSW events in the same sector.

Chen et al. (2016) studied the ionospheric disturbances during the 2013 SSW observed in eight locations on the meridional chain from $30.5^{\circ} \mathrm{N}$ to $42.8^{\circ} \mathrm{N}$ in northern China. They reported that the strongest disturbance occurred in Wuhan $\left(114.4^{\circ} \mathrm{E}, 30.5^{\circ} \mathrm{N} ; 25.1^{\circ} \mathrm{N}\right.$ geomagnetic latitude). Our results of $A_{M 2}$ during the $2009 \mathrm{SSW}$ are similar with them in the same latitudinal band, but are strongest in the EIA crest regions. Liu et al. (2011) studied the onset date of the semi-diurnal perturbations in the eastern Asia-Australia sector during the 2009 SSW with TEC data from three GNSS receivers, one on the geomagnetic equator and two near the EIA crests. They reported that such onset date tends to be about 2 days earlier in the northern hemisphere than in the southern hemisphere. Also, Tang et al. (2021) studied the ionospheric responses during the 2014 to 2015 SSW with ionosondes from Japan and Australia (mostly beyond $\pm 20^{\circ}$ geomagnetic latitudes). It is reported that the M2 modulation of $f o F 2$ occurred successively from relatively lower to higher latitudes in both hemispheres during the SSW. As a comparison, the latitudinal distribution of $A_{M 2}$ enhancement during the $2009 \mathrm{SSW}$ in Figs. 4 and 5 shows similar signatures as described in Liu et al. (2011) and Tang et al. (2021) in corresponding latitudinal regions.

Another thing worth noting is that the manifestation of TEC M2 perturbations during the 2009 SSW in the eastern Asia-Australia sector has both similarity and difference compared to that in the American sector. Figure 6 gives the variations of $A_{M 2}$ and $E R_{M 2}$ in the eastern AsiaAustralia and American sectors during the 2009 SSW. The vertical dashed lines are the same as those in Fig. 2a. The horizontal dashed lines represent the geomagnetic equator. Note that the $E R_{M 2}$ values are multiplied by ten (five) in Fig. 6c, $\mathrm{d}$ for facilitating quantitive comparisons between the eastern Asia-Australia and American sectors. The American results were calculated with the same method described in section 2, but with CEDAR Madrigal TEC map data (Rideout and Coster, 2006; Liu et al., 2021).

Figure $6 \mathrm{a}, \mathrm{b}$ shows that the latitudinal and interhemispheric differences of the $A_{M 2}$ variation are similar in the eastern Asia-Australia and American sectors as described hereinabove. Our previous paper (Liu et al., 2021) suggested that the latitudinal difference in the low latitude is largely contributed by the summer-winter meridional wind effect on the equatorial plasma fountain. We also discussed the possible contributions from the local geomagnetic configuration since the geomagnetic equator in the American sector is in the southern hemisphere. Comparatively, the geomagnetic equator in the eastern Asia-Australia sector is in the northern hemisphere. Thus, the similarity shown in Fig. 6a, b indicates that the latitudinal difference in the low latitude is not due to the local geomagnetic configuration.

Besides the similarity above, Fig. 6a, b shows that the magnitude of $A_{M 2}$ enhancement is larger in the American sector than in the eastern Asia-Australia sector. Such a longitudinal difference is consistent with the results from multi-case comparisons of TEC M2 perturbations around $10^{\circ} \mathrm{N}$ geomagnetic latitude between the eastern Asian and American sectors during 10 winter periods with different SSW levels (Liu et al., 2019) as well as results from other previous papers (Sathishkumar and Sridharan, 2013; Siddiqui et al., 2017). Such a difference may be attributed to a combined effect of longitudinal variations of atmospheric (especially tidal) and electrodynamic processes (Pedatella et al., 2012b; Yamazaki et al., 2017; Pedatella and Liu, 2013; Liu et al., 2011). For instance, Pedatella et al. (2012b) conducted Whole Atmosphere Community Climate Model simulations and found that the atmospheric M2 amplitude in December has clear longitudinal variability at low latitudes. Yamazaki et al. (2017) found clear longitudinal variability in the M2 amplitude in EEJ and suggested that it is partly caused by the longitudinal differences of ionospheric conductivities determined by the background geomagnetic field.

Meanwhile, Fig. 6c-e shows that the latitudinal distribution of $E R_{M 2}$ variations is distinctly different between the eastern Asia-Australia and American sectors. In the eastern Asia-Australia sector, the latitudinal distribution of $E R_{M 2}$ variation (Fig. 6c) is similar as that of $A_{M 2}$ (Fig. 6a). This indicates that the latitudinal variation of the ionospheric M2 tide is similar as that of the ionospheric solar tide in the eastern Asia-Australia sector during the 2009 SSW. Comparatively, the difference between Figs. $6 \mathrm{~b}$ and $6 \mathrm{~d}(6 \mathrm{e})$ indicates that the latitudinal variation of the ionospheric M2 tide is different from that of the ionospheric solar tide in the American sector.

Besides, Fig. 6c-e shows that the magnitude of $E R_{M 2}$ enhancement is also larger in the American sector than in the eastern Asia-Australia sector, which is similar as the manifestation of $A_{M 2}$ but more significant in the southern middle latitude. Considering that $E R_{M 2}$ represents the relative magnitude of M2 in comparison with solar tides, such results indicate that both the absolute and relative M2 effect in the ionosphere is stronger in the American sector than in the eastern Asia-Australia sector during the 2009 SSW. This is not only because that $A_{M 2}$ is relatively larger in the American sector than in the eastern Asia-Australia sector as shown in Fig. 6a, $\mathrm{b}$, but also because that the solar-tide amplitude is relatively smaller in the American sector than in the eastern 

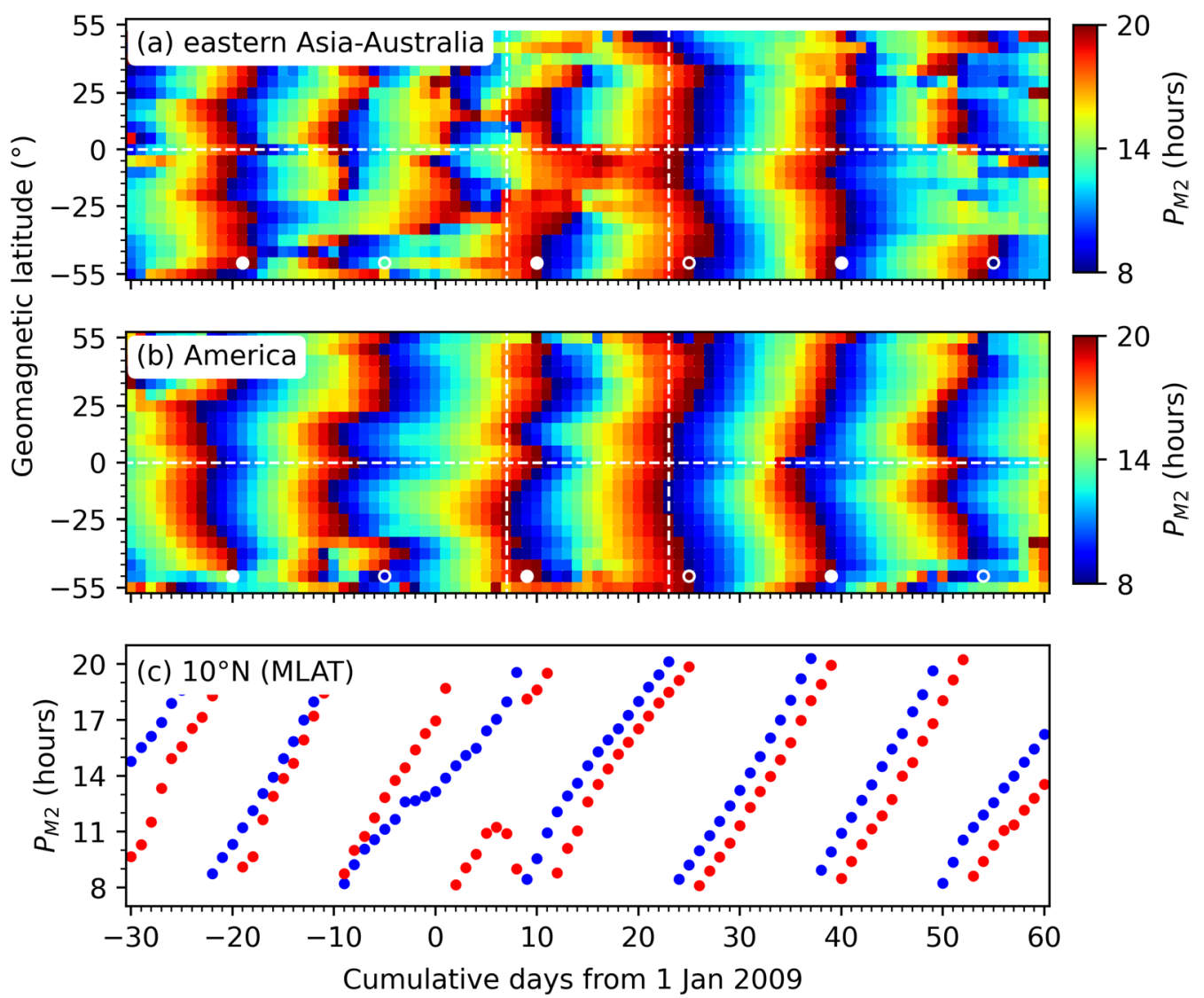

Fig. 7 The variations of $P_{M 2}$ in the $\mathbf{a}$ eastern Asia-Australia and $\mathbf{b}$ American sectors during the 2009 SSW. The dashed lines are the same as those in Fig. 6. c Gives the $P_{M 2}$ variations at $10^{\circ} \mathrm{N}$ geomagnetic latitude in the two sectors with red for the eastern Asia-Australia sector and blue for the American sector

Asia-Australia sector, especially in the southern middle latitude (figures not shown here).

In addition, clear $A_{M 2}$ extends to relatively higher latitudes (Fig. 6b) and the $E R_{M 2}$ is much larger in the southern middle latitude than in the low latitude (Fig. 6d, e) in the American sector compared to those (Fig. 6a, c) in the eastern Asia-Australia sector. It is worth noting that there is a unique ionospheric phenomenon named Weddell Sea Anomaly (WSA) (Penndorf, 1965; He et al., 2009; and references therein) in the American southern middle latitude. Liu et al. (2021) discussed the possible M2 wind modulation on the nighttime TEC in the WSA region during the 2009 SSW. The WSA is primarily attributed to the combined effect of the zonal wind and the positive geomagnetic declination which contributes to the geomagnetic northward wind that sustains the F-region plasma density (Penndorf, 1965; He et al., 2009; and reference therein). Thus, the contribution of the zonal tidal wind to the ionospheric variability in the WSA region may be much more significant than that in the eastern Asia-Australia sector where is no WSA-like phenomenon in the southern hemisphere during the same period. This may partly contribute to the differences of the ionospheric perturbations during the SSW between the eastern Asia-Australia and American sectors. Besides, the TEC M2 perturbations in the eastern Asia-Australia sector have local maxima in the southern middle latitude (Fig. 6a, c) while those in the American sector have similar features (Fig. 6d, e; Liu et al., 2021). This seems to indicate that the M2 influences on the ionosphere in the low latitude (mainly through fountain effect) and middle latitudes are not the same. Thus, it seems to support the possible contribution of the mechanism of direct wave upward penetration and in situ ionosphere modulation (Goncharenko and Zhang, 2008; Park and Lühr, 2012; Pedatella and Maute, 2015).

To further discuss the possible mechanism differences between the low and middle latitudes, Fig. 7 gives the $P_{M 2}$ variations in the (a) eastern Asia-Australia and (b) American sectors during the 2009 SSW. The dashed lines are the same as those in Fig. 6. Figure 7c gives the $P_{M 2}$ variations at $10^{\circ} \mathrm{N}$ geomagnetic latitude in the two sectors 
with red for the eastern Asia-Australia sector and blue for the American sector. In most cases, especially those corresponding to the latitudes and periods of the $A_{M 2}$ enhancement during the $2009 \mathrm{SSW}$, the $P_{M 2}$ in both sectors show periods with around half a lunar cycle (about 14.5 days). This further demonstrates that the 12.42-h component in our result is contributed by the M2 tide. In the eastern Asia-Australia sector, the $P_{M 2}$ in the middle latitudes tends to fall behind those in other latitudes. In the American sector, the $P_{M 2}$ in the EIA crest regions tends to advance those in other latitudes. The possible mechanism differences between the low and middle latitudes may lead to the phase differences. Nevertheless, the M2 amplitude and phase in the mesosphere and lowerthermosphere have significant latitudinal and interhemispheric differences (Pedatella et al., 2012a; and reference therein). Thus, such latitudinal and interhemispheric differences of the $P_{M 2}$ in the two sectors seem not enough to demonstrate the possible mechanism differences between the low and middle latitudes. Further studies, especially simulations, may be helpful for clarification. In addition, it seems that the $P_{M 2}$ in the eastern Asia-Australia sector falls behind that in the American sector for about 2 days during the 2009 SSW. This is illustrated more clearly in Fig. 7c between days 10 and 50 . Such feature is consistent with Fejer et al. (2010), in which they found that the EEJ perturbations during the SSW events occurred first in the American sector while several days later in the Pacific sector and attributed this phenomenon to the different effects of lunar tide in each sector.

\section{Summary}

Ionospheric perturbations in the eastern Asia-Australia sector are studied with TEC and foF2 during the 2009 SSW. Following the polar peak warming, distinct latitudinal and interhemispheric differences of M2 perturbations are revealed and compared with those in the American sector.

The most distinct M2 perturbations in TEC and $f_{o} F 2$, manifested as phase-shifted semi-diurnal (PSSD) signatures, occur near the EIA crest regions around $\pm 15^{\circ}$ geomagnetic latitudes. Clear PSSD perturbations extend to middle latitudes only in the southern hemisphere. The northern and southern $A_{M 2}, A_{M 2}$, and $E R_{M 2}$ maximize at around $15^{\circ} \mathrm{N}$ and $20^{\circ} \mathrm{S}$ geomagnetic latitudes, but their largest magnitude corresponds to the first and second PSSD cycles, respectively, i.e., corresponding to different moon phases. The southern $A_{M 2}$, $A_{M 2}$, and $E R_{M 2}$ also show local maxima around $35^{\circ} \mathrm{S}$ geomagnetic latitude.

The latitudinal and interhemispheric differences of M2 perturbations in the low latitude in the eastern AsiaAustralia sector are similar as those in the American sector. This supports our previous suggestion that such latitudinal and interhemispheric differences in the low latitude are primarily due to the summer-winter thermospheric wind effect on the equatorial plasma fountain. In addition, the manifestation of M2 perturbations in the southern middle latitude is much more significant in the American sector than in the eastern Asia-Australia sector, which indicates that the WSA-related thermospheric circulation may have influence on the lower atmosphereionosphere coupling process.

\section{Abbreviations \\ SSW: Sudden Stratospheric Warming; PW: Planetary wave; M2: Semi-diurnal lunar tide; PSSD: Phase-shifted semi-diurnal; GNSS: Global Navigation Satellite System; TEC: Total electron content; EEJ: Equatorial electrojet; EIA: Equatorial Ionization Anomaly.}

\section{Acknowledgements}

This study is supported by the projects of the Key Laboratory of Electro-magnetic Environment of China Research Institute of Radio-wave Propagation and Chinese Meridian Project. The authors would like to thank the data providers and all referees for help in evaluating this paper.

\section{Authors' contributions}

$J \mathrm{~L}$ and DZ mainly contributed to this study. $\mathrm{J}$ analyzed the data and drafted the manuscript. DZ contribute to the methodology and revision. SS, YH, and ZX provided suggestion. All the authors read and approved the final manuscript.

\section{Funding}

This research study was supported by the National Natural Science Foundation of China (42074192).

\section{Availability of data and materials}

The GNSS data were from the Crustal Dynamics Data Information System of the National Aeronautics and Space Administration (https://cddis.nasa.gov/). The ionosonde data were from the Chinese Meridian Project (https://data. meridianproject.ac.cn/) and the Space Weather Services of the Australian Government Bureau of Meteorology (https://www.sws.bom.gov.au/). The magnetometer data were from the Space Environment Research Center of Kyushu University (http://magdas2.serc.kyushu-u.ac.jp/index.html). The NCEP reanalysis data were from the Physical Sciences Laboratory of the National Oceanic and Atmospheric Administration (https://psl.noaa.gov/). The Kp and F10.7 indices data were from the Goddard Space Flight Center (https://omniw eb.gsfc.nasa.gov/).

\section{Declarations}

\section{Competing interests}

The authors declare that they have no competing interests.

\section{Author details}

${ }^{1}$ School of Earth and Space Sciences, Peking University, Beijing, China. ${ }^{2}$ China Research Institute of Radio-Wave Propagation, Qingdao, China.

Received: 23 September 2021 Accepted: 13 January 2022 Published online: 02 February 2022

\section{References}

Anderson D, Anghel A, Yumoto K, Ishitsuka M, Kudeki E (2002) Estimating daytime vertical ExB drift velocities in the equatorial F-region using ground-based magnetometer observations. Geophys Res Lett. https:// doi.org/10.1029/2001 gl014562 
Butler AH, Seidel DJ, Hardiman SC, Butchart N, Birner T, Match A (2015) Defining sudden stratospheric warmings. Bull Am Meteor Soc 96(11):19131928. https://doi.org/10.1175/bams-d-13-00173.1

Chau JL, Fejer BG, Goncharenko LP (2009) Quiet variability of equatorial E x $B$ drifts during a sudden stratospheric warming event. Geophys Res Lett 36(5):893. https://doi.org/10.1029/2008gl036785

Chen G, Wu C, Zhang S, Ning B, Huang X, Zhong D et al (2016) Midlatitude ionospheric responses to the 2013 SSW under high solar activity. J Geophys Res Space Phys 121(1):790-803. https://doi.org/10.1002/2015ja021980

Fagundes PR, Goncharenko LP, Abreu AJ, Venkatesh K, Pezzopane M, Jesus R et al (2015) lonospheric response to the 2009 sudden stratospheric warming over the equatorial, low, and middle latitudes in the South American sector. J Geophys Res Space Phys 120(9):7889-7902. https:// doi.org/10.1002/2014ja020649

Fang TW, Fuller-Rowell T, Akmaev R, Wu F, Wang H, Anderson D (2012) Longitudinal variation of ionospheric vertical drifts during the 2009 sudden stratospheric warming. J Geophys Res 117:A03324. https://doi.org/10. 1029/2011JA017348

Fang TW, Fuller-Rowell T, Wang H, Akmaev R, Wu F (2014) Ionospheric response to sudden stratospheric warming events at low and high solar activity. J Geophys Res Space Phys 119:7858-7869. https://doi.org/10. 1002/2014JA020142

Fejer BG, Olson ME, Chau JL, Stolle C, Lühr H, Goncharenko LP et al (2010) Lunar-dependent equatorial ionospheric electrodynamic effects during sudden stratospheric warmings. J Geophys Res Space Phys. https://doi. org/10.1029/2010ja015273

Forbes JM, Zhang X (2012) Lunar tide amplification during the January 2009 stratosphere warming event: observations and theory. J Geophys Res Space Phys. https://doi.org/10.1029/2012ja017963

Fuller-Rowell T, Akmaev R, Wu F, Fedrizzi M, Viereck RA, Wang H (2011) Did the January 2009 sudden stratospheric warming cool or warm the thermosphere? Geophys Res Lett. https://doi.org/10.1029/2011GL048985

Fuller-Rowell TJ, Fang T, Wang H, Matthias V, Hoffmann P, Hocke K, Studer S (2016) Impact of migrating tides on electrodynamics during the January 2009 sudden stratospheric warming. Ionospheric Space Weather. https:// doi.org/10.1002/9781118929216.ch14

Goncharenko L, Zhang S (2008) lonospheric signatures of sudden stratospheric warming: ion temperature at middle latitude. Geophys Res Lett 35(21):L15804. https://doi.org/10.1029/2008gl035684

Goncharenko LP, Coster AJ, Chau JL, Valladares CE (2010) Impact of sudden stratospheric warmings on equatorial ionization anomaly. J Geophys Res Space Phys. https://doi.org/10.1029/2010ja015400

Goncharenko L, Chau JL, Condor P, Coster A, Benkevitch L (2013) Ionospheric effects of sudden stratospheric warming during moderate-to-high solar activity: case study of January 2013. Geophys Res Lett 40(19):4982-4986. https://doi.org/10.1002/grl.50980

He M, Liu L, Wan W, Ning B, Zhao B, Wen J et al (2009) A study of the Weddell Sea Anomaly observed by FORMOSAT-3/COSMIC. J Geophys Res Space Phys. https://doi.org/10.1029/2009ja014175

He M, Chau JL, Stober G, Li G, Ning B, Hoffmann P (2018) Relations between semidiurnal tidal variants through diagnosing the zonal wavenumber using a phase differencing technique based on two ground-based detectors. J Geophys Res Atmospheres 123(8):4015-4026. https://doi.org/10. 1002/2018jd028400

Ho CM, Mannucci AJ, Lindqwister UJ, Pi X, Tsurutani BT (1996) Global ionosphere perturbations monitored by the Worldwide GPS Network. Geophys Res Lett 23(22):3219-3222. https://doi.org/10.1029/96gl02763

Kane RP (1973) An estimate of the equatorial electrojet strength. J Atmos Terr Phys 35(8):1565-1567. https://doi.org/10.1016/0021-9169(73)90157-8

Lin CH, Lin JT, Chang LC, Liu JY, Chen CH, Chen WH et al (2012) Observations of global ionospheric responses to the 2009 stratospheric sudden warming event by FORMOSAT-3/COSMIC. J Geophys Res Space Phys. https://doi. org/10.1029/2011ja017230

Liu H, Yamamoto M, Ram ST, Tsugawa T, Otsuka Y, Stolle C et al (2011) Equatorial electrodynamics and neutral background in the Asian sector during the 2009 stratospheric sudden warming. J Geophys Res Space Phys. https://doi.org/10.1029/2011ja016607

Liu J, Zhang D-H, Hao Y-Q, Xiao Z (2019) The comparison of lunar tidal characteristics in the low-latitudinal ionosphere between East Asian and American sectors during stratospheric sudden warming events: 2009-2018. J Geophys Res Space Phys. https://doi.org/10.1029/2019ja026722
Liu J, Zhang D, Mo X, Xiong C, Hao Y, Xiao Z (2020) Morphological differences of the northern equatorial ionization anomaly between the Eastern Asian and American Sectors. J Geophys Res Space Phys. https://doi.org/10. 1029/2019ja027506

Liu J, Zhang D, Goncharenko LP, Zhang S, He M, Hao Y, Xiao Z (2021) The latitudinal variation and hemispheric asymmetry of the ionospheric lunitidal signatures in the American sector during major Sudden Stratospheric Warming events. J Geophys Res Space Phys. https://doi.org/10.1029/ 2020ja028859

Manney GL, Schwartz MJ, Krüger K, Santee ML, Pawson S, Lee JN, Livesey NJ (2009) Aura Microwave Limb Sounder observations of dynamics and transport during the record-breaking 2009 Arctic stratospheric major warming. Geophys Res Lett 36(12):L12815. https://doi.org/10.1029/2009G L038586

Matsuno T (1971) A Dynamical Model of the Stratospheric Sudden Warming. J Atmos Sci 28(8):1479-1494. https://doi.org/10.1175/1520-0469(1971) 028\%3c1479:admots\%3e2.0.co;2

Mo XH, Zhang DH (2018) Lunar tidal modulation of periodic meridional movement of equatorial ionization anomaly crest during sudden stratospheric warming. J Geophys Res Space Phys 123(2):1488-1499. https://doi.org/ 10.1002/2017ja024718

Mo X, Zhang D, Goncharenko L, Zhang S, Hao Y, Xiao Z et al (2017) Meridional movement of northern and southern equatorial ionization anomaly crests in the East-Asian sector during 2002-2003 SSW. Sci China Earth Sci 60(4):776-785. https://doi.org/10.1007/s11430-016-0096-y

Park J, Lühr H (2012) Effects of sudden stratospheric warming (SSW) on the lunitidal modulation of the F-region dynamo. J Geophys Res Space Phys. https://doi.org/10.1029/2012ja018035

Park J, Lühr H, Kunze M, Fejer BG, Min KW (2012) Effect of sudden stratospheric warming on lunar tidal modulation of the equatorial electrojet. J Geophys Res Space Phys. https://doi.org/10.1029/2011ja017351

Pedatella NM, Forbes JM (2010) Evidence for stratosphere sudden warmingionosphere coupling due to vertically propagating tides. Geophys Res Lett. https://doi.org/10.1029/2010gl043560

Pedatella NM, Liu H-L (2013) The influence of atmospheric tide and planetary wave variability during sudden stratosphere warmings on the low latitude ionosphere. J Geophys Res Space Phys 118:5333-5347. https://doi. org/10.1002/jgra.50492

Pedatella NM, Maute A (2015) Impact of the semidiurnal lunar tide on the midlatitude thermospheric wind and ionosphere during sudden stratosphere warmings. J Geophys Res Space Phys 120(12):10740-10753. https://doi. org/10.1002/2015ja021986

Pedatella NM, Liu HL, Richmond AD (2012a) Atmospheric semidiurnal lunar tide climatology simulated by the Whole Atmosphere Community Climate Model. J Geophys Res Space Phys. https://doi.org/10.1029/2012j a017792

Pedatella NM, Liu H-L, Richmond AD, Maute A, Fang T-W (2012b) Simulations of solar and lunar tidal variability in the mesosphere and lower thermosphere during sudden stratosphere warmings and their influence on the low-latitude ionosphere. J Geophys Res Space Phys. https://doi.org/10. 1029/2012ja017858

Pedatella NM, Liu H-L, Sassi F, Lei J, Chau JL, Zhang X (2014) lonosphere variability during the 2009 SSW: influence of the lunar semidiurnal tide and mechanisms producing electron density variability. J Geophys Res Space Phys 119(5):3828-3843. https://doi.org/10.1002/2014ja019849

Pedatella NM, Fang T-W, Jin H, Sassi F, Schmidt H, Chau JL et al (2016) Multimodel comparison of the ionosphere variability during the 2009 sudden stratosphere warming. J Geophys Res Space Phys 121(7):7204-7225. https://doi.org/10.1002/2016ja022859

Penndorf, R. (1965). Antarctic Research Series, p. 1-45. https://doi.org/10.1029/ ar004p0001

Rastogi RG, Klobuchar JA (1990) Ionospheric electron content within the equatorial F 2 layer anomaly belt. J Geophys Res Space Phys 95(A11):19045-19052. https://doi.org/10.1029/ja095ia11p19045

Rideout W, Coster A (2006) Automated GPS processing for global total electron content data. GPS Solutions 10(3):219-228. https://doi.org/10.1007/ s10291-006-0029-5

Saito A, Fukao S, Miyazaki S (1998) High resolution mapping of TEC perturbations with the GSI GPS Network over Japan. Geophys Res Lett 25(16):3079-3082. https://doi.org/10.1029/98gl52361 
Sathishkumar S, Sridharan S (2013) Lunar and solar tidal variabilities in mesospheric winds and EEJ strength over Tirunelveli $\left(8.7^{\circ} \mathrm{N}, 7.78^{\circ} \mathrm{E}\right)$ during the 2009 major stratospheric warming. J Geophys Res Space Phys 118(1):533-541. https://doi.org/10.1029/2012ja018236

Shepherd SG (2014) Altitude-adjusted corrected geomagnetic coordinates: definition and functional approximations. J Geophys Res Space Phys 119(9):7501-7521. https://doi.org/10.1002/2014ja020264

Siddiqui TA, Stolle C, Lühr H (2017) Longitude-dependent lunar tidal modulation of the equatorial electrojet during stratospheric sudden warmings. J Geophys Res Space Phys 122(3):3760-3776. https://doi.org/10.1002/ 2016ja023609

Siddiqui TA, Yamazaki Y, Stolle C, Maute A, Laštovička J, Edemskiy IK et al (2021) Understanding the total electron content variability over Europe during 2009 and 2019 SSWs. J Geophys Res Space Phys. https://doi.org/10.1029/ 2020ja028751

Tang Q, Zhou C, Li Z, Liu Y, Chen G (2021) Semi-monthly lunar tide oscillation of foF2 in equatorial ionization anomaly (EIA) crests during 2014-2015 SSW. J Geophys Res Space Phys. https://doi.org/10.1029/2020ja028708

Tsugawa T, Saito A, Otsuka Y, Yamamoto M (2003) Damping of large-scale traveling ionospheric disturbances detected with GPS networks during the geomagnetic storm. J Geophys Res Space Phys. https://doi.org/10. 1029/2002ja009433

Vineeth C, Pant TK, Kumar KK, Ramkumar G, Sridharan R (2009) Signatures of low latitude-high latitude coupling in the tropical MLT region during sudden stratospheric warming. Geophys Res Lett. https://doi.org/10. 1029/2009gl040375

Xiong J, Wan W, Ding F, Liu L, Ning B, Niu X (2013) Coupling between mesosphere and ionosphere over Beijing through semidiurnal tides during the 2009 sudden stratospheric warming. J Geophys Res Space Phys 118(5):2511-2521. https://doi.org/10.1002/jgra.50280

Yamazaki Y, Richmond AD, Yumoto K (2012) Stratospheric warmings and the geomagnetic lunar tide: 1958-2007. J Geophys Res Space Phys. https:// doi.org/10.1029/2012ja017514

Yamazaki Y, Stolle C, Matzka J, Siddiqui TA, Lühr H, Alken P (2017) Longitudinal variation of the lunar tide in the equatorial electrojet. J Geophys Res Space Phys 122(12):12445-12463. https://doi.org/10.1002/2017ja024601

Yamazaki Y, Stolle C, Siddiqui T, Laštovička J, Mošna Z, Kozubek M, Ward W, Themens D, Kristoffersen S (2020) VERA: VERtical coupling in Earth's Atmosphere at mid and high latitudes; Final Report. Potsdam: German Research Centre for Geosciences GFZ, p. 138. https://doi.org/10.2312/ GFZ.2.3.2020.001

Yue X, Schreiner WS, Lei J, Rocken C, Hunt DC, Kuo Y, Wan W (2010) Global ionospheric response observed by COSMIC satellites during the January 2009 stratospheric sudden warming event. J Geophys Res Space Phys. https://doi.org/10.1029/2010ja015466

Zhang DH, Xiao Z (2005) Study of ionospheric response to the $4 \mathrm{~B}$ flare on 28 October 2003 using International GPS Service network data. J Geophys Res Space Phys. https://doi.org/10.1029/2004ja010738

Zhang W, Zhang DH, Xiao Z (2009) The influence of geomagnetic storms on the estimation of GPS instrumental biases. Ann Geophys 27(4):16131623. https://doi.org/10.5194/angeo-27-1613-2009

Zhang DH, Zhang W, Li Q, Shi LQ, Hao YQ, Xiao Z (2010) Accuracy analysis of the GPS instrumental bias estimated from observations in middle and low latitudes. Ann Geophys 28(8):1571-1580. https://doi.org/10.5194/ angeo-28-1571-2010

\section{Publisher's Note}

Springer Nature remains neutral with regard to jurisdictional claims in published maps and institutional affiliations.

\section{Submit your manuscript to a SpringerOpen ${ }^{\circ}$ journal and benefit from:}

- Convenient online submission

- Rigorous peer review

- Open access: articles freely available online

- High visibility within the field

- Retaining the copyright to your article

Submit your next manuscript at $\boldsymbol{\Delta}$ springeropen.com 